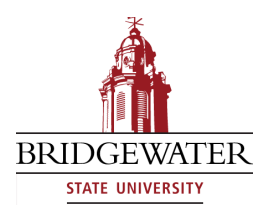

Journal of International Women's Studies

\title{
Rethinking Patriarchy, Culture and Masculinity: Transnational Narratives of Gender Violence and Human Rights Advocacy
}

Elora Halim Chowdhury

Follow this and additional works at: https://vc.bridgew.edu/jiws

Part of the Women's Studies Commons

\section{Recommended Citation}

Chowdhury, Elora Halim (2015). Rethinking Patriarchy, Culture and Masculinity: Transnational Narratives of Gender Violence and Human Rights Advocacy. Journal of International Women's Studies, 16(2), 98-114. Available at: https://vc.bridgew.edu/jiws/vol16/iss2/6

This item is available as part of Virtual Commons, the open-access institutional repository of Bridgewater State University, Bridgewater, Massachusetts.

This journal and its contents may be used for research, teaching, and private study purposes. Any substantial or systematic reproduction, re-distribution, re-selling, loan or sub-licensing, systematic supply, or distribution in any form to anyone is expressly forbidden. Authors share joint copyright with the JIWS. (C2022 Journal of International Women's Studies. 
This journal and its contents may be used for research, teaching and private study purposes. Any substantial or systematic reproduction, re-distribution, re-selling, loan or sub-licensing, systematic supply or distribution in any form to anyone is expressly forbidden. (C2015 Journal of International Women's Studies.

\title{
Rethinking Patriarchy, Culture and Masculinity: Transnational Narratives of Gender Violence and Human Rights Advocacy
}

\author{
By Elora Halim Chowdhury ${ }^{1}$
}

\begin{abstract}
In this paper, I argue that to truly understand the complexity and "high prevalence" of acid violence against women in Bangladesh, we must pay attention to the confluence of political, economic and historical forces that make certain social groups more vulnerable to such extreme violence and suffering. By tracing the life history narratives of survivors of gender-based violence, I hope to shed light that acid throwing - a form of gendered violence - has to be understood beyond a "culturalist" framework, which explains this phenomenon as a product of harmful patriarchal cultural practices, seemingly more prevalent in certain South Asian cultures. Rather, I argue, acid violence has to be understood within a broader "structural inequality" framework, which maps the vulnerability of the victims onto their life trajectory shaped by complex forces of globalization, neoliberal development, patriarchy and poverty. Focusing on the systemic oppressions faced by vulnerable social groups whether embedded in family, kin and community structures or the global capitalist system, I argue that mapping a trajectory of suffering can aid in imagining a more nuanced and humane transnational analytic and response with regards to violence against women.
\end{abstract}

Key Words: Gender Violence, Culture, Masculinity, Narrative Analysis

\section{Introduction}

Chronicling the vulnerability and suffering of marginalized populations in Haiti, the poorest country in the Western Hemisphere, researcher Paul Farmer (2005) asks the critical question, "By what mechanisms, precisely, do social forces ranging from poverty to racism become embodied as individual experience?" (p. 369). A remarkable feature of Farmer's analysis includes charting the biographies of victims of violence to bring to light the trajectory of suffering they experienced as a consequence of their gendered vulnerabilities. Farmer underscores the point that, "Social forces at work [in Haiti] have also structured risk for most forms of extreme suffering, from hunger to torture and rape" (p. 369). He demonstrates that in order to truly understand how and why certain victims met with tragic deaths by AIDS and political violence, one has to further contextualize their lives within the intersecting axis of colonialism, poverty, racism, and sexism. Farmer's methodological approach enables us to

\footnotetext{
${ }^{1}$ Elora Halim Chowdhury is an Associate Professor in the Department of Women's and Gender Studies at the University of Massachusetts Boston. Her research and teaching interests include transnational feminisms, gender and development, violence and human rights advocacy in South Asia. She is the author of Transnationalism

Reversed: Women Organizing Against Gendered Violence in Bangladesh (SUNY Press, 2011), which was awarded the Gloria E. Anzaldua book prize by the National Women's Studies Association in 2012. She has published widely in peer-reviewed journals and edited anthologies. Her current scholarship focuses on dissident cross-border feminist alliances, friendships, and solidarity projects.
} 
understand violence as gendered and structural as opposed to an act encapsulated within the contours of a single incident.

In this article, I will argue that to truly understand the complexity and prevalence of the phenomenon of acid attacks and other violence against individual women and girls in South Asia, we must pay attention to the confluence of political, socioeconomic and historical forces that make certain social groups more vulnerable to such extreme violence and suffering. By examining case studies of survivors in the Acid Survivors Foundation Bangladesh commissioned report, Conflict Dynamics of Acid Violence: 10 Case Studies on Conflicts Dynamics of Acid (Patriarchal) Violence in Bangladesh (Acid Survivors Foundation, 2007), I hope to shed light on the way that acid throwing - a form of gendered violence-must be understood beyond the "culturalist" framework that predominantly shapes transnational human rights campaigns for gender justice. These campaigns rely on narratives that are made intelligible as human rights stories through the deployment of ideological and hegemonic categories of patriarchy and cultural difference. Through a powerful transnational media circuit, these concepts are assumed to be a logical analytic framework to explain why violence against women is seemingly more prevalent in certain cultures - namely those in the Global South. Instead, I believe that acid violence has to be understood within a broader "structural inequality" framework, which maps the vulnerability of the victims onto their life trajectories shaped by multiple complex forces of globalization, patriarchy and poverty. Deploying multi-disciplinary theoretical and methodological approaches including discourse, narrative and political economic analysis, and the use of primary and secondary sources, I argue the importance of examining historical, economic, cultural and political processes that make certain social groups more vulnerable to extreme violence. In addition, by examining the frames of gender violence deployed in narratives of human rights within NGO-reports, I want to draw out the underlying assumptions shaping responses to this phenomenon mounted by the state and transnational activist networks. Focusing on the systemic oppressions faced by vulnerable social groups and considering their contextual realities will aid in the development of what Karin Landgren (2005) describes as a more "protective environment" for marginalized populations to live freer of abuse, exploitation and violence.

\section{Narrative and Human Rights Campaigns}

In this paper, I want to draw attention to the importance of stories and testimonials in human rights campaigns, the ability of narratives in presenting experiential truths as well as in strategic mobilizing, and the ways in which human rights narratives contribute to both assisting and impeding transnational movement building. Though testimonials and stories are inherently about the individual, like Farmer, I am interested in the ways in which analyzing the life trajectories of an individual can be used to illuminate the structural factors related to gendered violence. To do so, I draw on recent case studies compiled in Conflict Dynamics of Acid Violence, commissioned by the Acid Survivors Foundation in Dhaka Bangladesh with the explicit objective to engender greater understanding of the phenomenon of acid violence and to offer recommendations to address it. The analysis of the narratives in this paper is an attempt to further discussions on more effective transnational human rights advocacy with regards to gender violence. It is not my intention to assess the authenticity or value of the narratives, but rather to bring attention to the processes of narrative construction, interpretation, circulation, and reception in order to demonstrate how all of these registers are imbued in power relations that 
shape and inform human rights campaigns. Furthermore, I deploy a transnational feminist analysis, which illuminates the far-reaching relations of domination and oppression in these every day narratives (Stone-Mediatore, 2002).

Conflict Dynamics of Acid Violence locates the root cause of acid violence in patriarchy and hegemonic masculinity. Even though the report lists myriad factors contributing to acid attacks including material interests, lack of women's rights, political instability, and capitalist development in the region, it prioritizes a 'common sense' logic of patriarchal values and attitudes as the main cause of violence against women. It suggests that marriage and kinship systems form the core of societal organization in Bangladesh. These systems are derivative of feudal patriarchal arrangements, which when threatened, lead to expressions of hegemonic masculinities manifested through domination and control. Additionally, the report brands acid violence as a crime limited mostly to the rural and lower socio-economic groups. While this may be the case for acid violence in particular, another recent survey conducted by the Government of Bangladesh and sponsored by the United Nations Population Fund (UNFPA) has confirmed domestic violence against women in Bangladesh transcends class, religion, and the rural-urban divide. An astonishing $87 \%$ of married women in this survey reported abuse (Hossain, 2014). In this context, to label acid violence against women as a problem inflicting the poor populations contributes to the overall sentiments in the region that poverty and violence are naturally intertwined, and that acid violence is a form of exceptional violence. The ASF report choses to make this claim based on the method of inflicting harm on women: that is, the use of acid as a weapon with the express desire to disfigure women. Here too, the report suggests that the use of acid is a particular choice made by men socialized to enact hegemonic masculinity in a patriarchal society. Acid as a weapon is intended to destroy the feminine self and subjectivity of the target by permanently disfiguring women's bodies. Because of the population of the men in question-undereducated, under- or unemployed - the aggression is understood to be a pathology of men who want to assert power and domination to compensate their experiences of insufficient masculinity.

The report also places substantive blame on the perpetrators' psychosocial temperament and suggests that many of them might suffer from 'personality problems.' Based on interviews with male perpetrators currently in prison, the report also concludes that these personality problems might explain their propensity towards violence. The report states, "Also most men had some deeply ingrained psychic hatred towards women folk and wanted to "punish" them for whole life. The attitude might be related to their social upbringings" (p. 5). In addition, the report finds that the six perpetrators interviewed for this study came from large families and low socioeconomic backgrounds "where there is no basic education including moral teachings" (p. 35). Spiritual practice among the group was low and they also had contacts to local political parties. While none of them had "specific mental illness...they had a personality profile in which they had intolerance and low frustration threshold to other people's attitude, feelings, likings and disliking" (p. 5).

Contrary to the report's position on acid violence as an exceptional form of violence enacted by poor men on women, I would argue that while the use of acid as a weapon in the desire to disfigure the victim might be more highly prevalent in poor communities, the intent behind the crime cannot be reduced to a pathology of the poor. Certainly, the report provides no explanation regarding the causal link it makes between low socioeconomic status and lack of moral teachings. In 2011, the domestic abuse suffered by Rumana Monzur, Assistant Professor at Dhaka University and a graduate student in Politics at the University of British Columbia, 
Canada made national and international headlines. Her husband Hasan Sayeed Sumon, an unemployed engineer, brutally attacked her in the presence of their 5-year old daughter in the home of Monzur's parents because he did not want her to pursue a $\mathrm{PhD}$ degree. He later justified his actions by accusing her of being unfaithful. His intention was to disfigure and disable his wife in order to end her public and professional life and jeopardize her career goals. Elsewhere, I have written extensively about the intent behind men's acid throwing against women to be an attempt to end their public lives and their economic and social mobility (Chowdhury, 2011). Here, this case helps broaden our understanding of gender violence as complex-involving cultural (symbolic) as well as economic and political (material) inequalities, and cutting across class, education and rural/urban divides. Hasan Sayeed Sumon, an educated, middle-class male did not use acid as the chosen weapon but the intent and consequences were similar. Six months following the attack on Monzur, Rafiqul Islam, a Bangladeshi migrant worker in UAE cut off his wife, Hawa Akhter's, fingers of her right hand so she could not sit for her college exam. One newspaper reports, "The incident is one of a number of acts of domestic violence targeting educated women in recent months" (Ethirajan, 2011). Monzur commented in an interview with $\mathrm{CBC}$ news that, "When you belong to the privileged class, you never think domestic violence can happen to you" (Wells, 2011). Extreme violence is not limited to the poor or under-educated and neither is the motive to disfigure and disable women as a means to end their social and economic mobility. Banu's story in the ASF report follows a similar trajectory of long-term abuse accompanied by jealousy and suspicion, ultimately leading to the acid attack. Banu was a migrant domestic worker in Kuwait whose husband, on her return, "checked" her uterus to find out whether or not she was pregnant by another man. He was convicted of the crime of acid throwing and continued to harass his wife by sending letters with messages like "who can love has the right to hit" (ASF, 2007, p. 32) These were neither 'crimes of passion' nor caused by poverty as cases of extreme violence are often characterized because we know, in each situation, the act of disfiguring/marking was preceded by years of abuse known to the families. Such abuse is routinely sanctioned by family, community and society who expect women to abide by social codes of femininity like obedience and compromise (maniye cholo) (Saleh, 2011).

Contrary to the assumption that violence against women is more prevalent in 'traditional cultures' where misogyny is embedded in family and kinship structures (see for instance, Asra Nomani's (2011) evaluation of Rumana Monzur case as 'honor crime'), my analyses of the three examples above and of the ASF-case studies departs from existing understanding of gender violence and human rights advocacy in two key ways. First, they highlight how the risk of violence increases when women move beyond existing gender norms. Second, they show how violence coincides with significant transformations in gender relations. Together, these insights challenge a predominant narrative that links gendered violence in developing countries like Bangladesh with tradition and cultural stasis and within the intimate realm of the family. Instead, it points to the possibility that violence indexes exactly the opposite: societal transformations occurring in the economic and cultural realms and the resistance to these shifts that encompass the larger publics. More women in Bangladesh are now educated and more are joining the labor force. Social mobility for women can actually incite more violence, especially for those who are more educated or better employed when traditional forms of social control become ineffective.

Therefore, it is analytically dangerous, I believe, to relegate broader economic and political forces that impede women's human rights to peripheral causes of gender violence as is done in the ASF report. Further, locating the reasons in men's psychosocial (pre)disposition and within low socio-economic groups takes attention away from the fact that violence against 
women cuts across class and urban-rural divides in Bangladesh, and makes it an individual rather than structural problem. It reifies anti-poor and anti-rural myths that these populations are excessively patriarchal and backwards and unable to transcend traditional culture that sanctions violence against women. Inderpal Grewal (2013) has recently argued patriarchy as an analytic concept has been 'outsourced' by Western (U.S.) and urban Indian locales and relegated to distant national and rural cultures respectively. What this outsourcing achieves is to make a static patriarchy the site of the problem, which then has to be overcome by the backward regions of the world. She argues that this kind of analysis forecloses the possibility of more nuanced, historicized and conflictual kinds of analyses particularly in relation to 'spectacular violence.' Grewal looks at the production of the concept of 'honor killings' in transnational media circuits and critiques how, where, and when violence against women gets named as a specific crime.

Similarly, 'acid violence' against women evokes a particular meaning, identity and culture that follow a class and racial logic in the media. The ways in which such crimes enter popular consciousness are thoroughly mediated by a transnational circuit where culture and patriarchy are coded as difference, excessively so in regions such as the Middle East and South Asia. A closer look into human rights reporting - particularly NGO documents - reveals the term acid violence is deeply ideological. The implicit and sometimes explicit assumption is that patriarchal violence is an expression of hegemonic masculinity and happens exclusively in the context of an unchanging traditional culture where men are motivated by emotions like unbridled anger and jealousy. 'Modern' men however, whether in urban or western contexts, are above such pathological expressions. The astounding rates of violence against women in the U.S. and in urban locales such as Dhaka completely belie these powerful myths. This lazy treatment of patriarchy as essential while overlooking economic and political issues can serve to generate only partial and often misguided recognition of gender violence as a complex phenomenon.

Despite its short-sighted portrayal of the relationship between poverty, tradition, and violence, an important contribution of the ASF report is that it counters the myth that acid attacks are 'crimes of passion' committed by young men who are driven to the edge of sanity when rejected by their love-interests. Instead, like in the case of Banu's case cited above, and in others in the report, it is evident that the perpetrator(s) planned the attack and chose acid as the weapon in order to inflict a certain kind of damage - disfigurement, marking the body - as opposed to murder. In that sense, the crime is certainly patriarchal, encompassing a relation of hierarchy and subordination and expressing control through masculine behavior. However, patriarchy alone as an analytic category may not adequately explain the phenomenon of acid violence. In at least eight of the cases described in the ASF report, it is evident that the underlying reasons leading to the attack included disputes over property and money, family conflict, ethnic tensions, and political clout or lack thereof. Two of the victims were male, and in two cases women were splashed with acid by men who wanted to marry them and were rejected by the women's families, rather than being rejected by the women themselves. The attacks in all ten cases were preceded by verbal and in some cases physical abuse, threats and intimidation and longer periods of ongoing disputes in some instances, which shows that the violence is not a singular act motivated by blinding rage rather a calculated and planned course of action.

\section{Shukhibanu's Story}

The longest case study in the ASF report is one that maps the life trajectory of a twentyfive year old woman, Shukhibanu, and it is instructive because it enables an analysis of the 
confluence of factors leading to her gendered vulnerability and victimization. Shukhibanu was an orphan who was raised by her elder siblings. Not wanting to be a burden to her sister's family, she left their home and made her way to Dhaka. There, she met a woman whom she refers to as 'Apa.' Apa took her in and found her a job in a garment factory. For four years, she worked in the garment factory and dutifully handed over all her earnings to this woman. She moved up the ranks from helper to operator and earned Tk. 5000/month. Apa arranged her marriage to a day laborer and Shukhibanu began giving her salary to her father-in-law and husband. Eventually she found out that her husband had a wife and two children in his village home. When Shukhibanu had a daughter, she ended up taking care of all three children as the first wife "cut off her relationship with their [the children's] father." Despite Shukhibanu's clear disappointment in her husband's deceptions and other abuses, she says, "Then I made myself understand that once I got married then nothing remains in life. I decided to be with him." Shukhibanu's in-laws began pressuring her to bring money from her brothers, but this money was neither 'enough' for her husband and in-laws nor put to good use. When she moved in with her brothers, her husband made her return to his house despite the brothers' objections. Surprisingly, Shukhibanu took her husband's side in this argument and told her brother, "He is my husband. If I do anything wrong, he has the right to punish me." Verbal harassment and beatings continued. Her husband brought his first wife home, and when Shukhibanu objected her father-in-law said, "This is what is called punishment for not bringing money from your father's house. From now on, you two wives will have to be in this house together. You both have to work in the garments factory. It will be judged who is good, who is bad, and who can survive the test" (p.14). All of Shukhibanu's earnings were controlled by her in-laws and even after many years of backbreaking labor in the garment factory she was not able to save anything for her daughter. When she bought a pair of jeans and a shirt for her daughter, her husband became very angry and asked, "why on earth should you buy pant shirt for a girl?" Shukhibanu describes her situation as "my life is shattered, earnings are finished. I could not fulfill my smallest desire of buying a gift for my daughter." She declared that she would give her husband her earnings but no longer "provide any services as his wife.' She began to spend her nights at her landlord's house with his mother instead of with her husband. It is at this juncture her husband poured acid on Shukhibanu at night while she slept.

While common assumptions about violence blame patriarchal structures like inequality in marriage as well as a lack of "moral teachings" that result in personality problems in individuals, applying a life trajectory analysis in Shukhibanu's case can illuminate broader social structures that exacerbate gender-based violence. A structural reading of Shukhibanu's life trajectory reveals that she did not have family/patriarchal provision and protection from an early age, which is what led her to what appears to be a benevolent patriarchal situation where she deposited her earnings and salary to the 'Apa' who provided her with shelter and a job. She arranged her marriage to a day laborer who then turned to his wife to provide a steady source of income. It is through her earnings she bought her husband a rickshaw and a cow. Family/patriarchal protection was always tenuous for Shukhibanu even though she held on to its elusive structure. She overlooked her husband's deceptions and even acquiesced to his abuse by telling her brother that her husband (provider/protector) had the right to 'punish' her. Yet unable to secure any financial security in this marriage, she finally refused to perform her 'wifely' duties. Her husband was on the one hand angered that Shukhibanu chose to buy a jean pant and shirt for their daughter (Western garment and linked to the overall anxiety over women's emancipation rhetoric through NGOization and neoliberal economic development such as garment factories with primarily female employment), and secondly humiliated in front of 
neighbors when she refused to sleep with him. The first defied his control of her earnings, and the second denied him access to her body.

The choice of acid as weapon is symbolic at multiple levels. It disfigures (so Shukhibanu will no longer be desirable to anyone else), permanently marks (leaves an imprint on her body of the violence that is intended to shame her for defying his authority) and potentially impairs vision and hearing (she is no longer readily employable and thus inhibiting her economic mobility as well as social mobility). The use of acid needs to be contextualized within the shift to more modern economies and rapidly industrializing societies, like that of Bangladesh. Sulfuric and nitric acid are widely, cheaply and easily available from auto mechanic stores, leather factories, garment factories and jewelry shops. Studies in Bangladesh link those areas with high frequency of acid attacks to the existence of higher number of facilities that use acid (Chowdhury, 2011). These economic and social initiatives have made women central to the vision of development in South Asia. The targeted integration of women into industrialization with the concomitant under and unemployment of men have weakened male provision/protection and shifted gender norms and practices. It was Shukhibanu who was the primary wage-earner in her household although her economic mobility did not alter her social roles/value. Can/should human rights reporting prioritize culture and patriarchy over the societal transformations linked to such modernizing processes, or are they intricately interwoven? What purpose do such culturalist life narratives like the ones in the ASF report serve in activating human rights advocacy?

\section{Narrative, Violence, and Human Rights}

Kay Schaffer and Sidonie Smith (2004) as well as Wendy Hesford (2004) have developed critiques of the use of life narratives in human rights campaigns, frequently in tandem with transnational media circuits contributing to spectacularizing "third world violence," in the service of generating public response, yet at the same time reinscribing problematic and simplistic generalizations. Schaffer and Smith define life narrative as a broad term encompassing a range of personal storytelling based on the experiential (p.7). Hesford locates the deployment of the genre of life narratives, or "testimonio," specifically within the transnational human rights movement. These testimonials, often by victims of gender violence in third world contexts, play a key role in advancing an international human rights agenda by mobilizing diverse publics into action, even as they further romanticize spectacularized renditions of the speaking subject. Hesford cautions that scholars and practitioners must account for the "ungovernability of trauma and the methodological and ethical crises posed by its representation" (p. 106). This means recognizing that documentations, interpretations, circulations, receptions, and representations of trauma narratives cannot be contained and are always incommensurable. She terms this instability of narrative genre a crisis of reference to mean "the inability of representation to capture, as in fix or make static, the truth" leading to difficulty in using these narratives within human rights campaigns to persuade legal and social action (p. 107).

The mediated nature of life narratives or the intersubjectivity of them has pushed transnational feminist studies to consider not only the social location of the writer, or the "speaking subject," but also the circumstances in which the text is produced. The critical negotiation involved in the struggle within which trauma narratives are told, listened to, and interpreted occur within "available cultural and national scripts and truth-telling conventions" (Hesford, 2004, p. 108). Here, the ASF commissioned report is a vehicle for furthering 
awareness, generating support and resources, and recommending responses to acid violence. The discursive subjectivity and agency of the narrator, the Foundation itself, and the ethical responses the narratives evoke from diverse actors are shaped within such rhetorical conventions. Elsewhere, I have written about the donor-driven agenda of the ASF and how it espouses a neoliberal vision of rehabilitating victims to reintegrate them into the productive machinery of the state (Chowdhury, $2005 \&$ 2011). This particular vision in animating action and advocacy, I have argued, locates the oppression of women in hegemonic notions of culture and patriarchy; however, it does not recognize the structural violence embedded in individual acts of violence.

Of particular interest to this discussion are the ways in which "distant" narratives of trauma and suffering are mediated within international human rights regimes, as are the strategies and methodologies that render intelligible the experiences of "foreign subjects" in local and transnational sites. Pointing to the success of linking local campaigns of gender violence to transnational movements of human rights, Shaffer and Smith (2004) remind us that, "In these instances, transits between the local and global and within pockets of modernity involve complex negotiations of traditional and modernist discourses and practices. In other instances, stories may be framed within traditional, communal, religious, or philosophic frameworks different from, but arguably consonant with, modernist aspirations for human dignity and social justice" (p. 17). In other words trauma narratives located at the intersection of local and global spaces might rely on "common sense" scripts but also throw into crisis existing paradigms of cross-border communications. Shukhibanu's testimony in the ASF commissioned report can be deployed in explaining acid violence against women in the dual registers of 'backward rural patriarchy' and 'aberrant third world patriarchy' yet is ultimately narrowly located within a discourse that does not open up discussions of complex, layered structural conditions of vulnerability. Anthropologist Sally Merry (2009) argues that "violence in intimate relationships is inseparable from societal conflict, violence, and injustice," and that gender violence is embedded not only in kinship and family structures but just as much within economic and political inequalities (p. 2). In other words, gender violence is inextricably linked to structural violence. Narratives, like the ones in the report, are gendered life trajectories and ought to be understood at the intersection of political protectionism, globalization, poverty and sexism.

While most media reports focus on younger, often adolescent, women being burned by rejected suitors, this demographic makes up less than a quarter of all acid attack cases in Bangladesh. Despite the numerical minority, it is this profile that has been highlighted most persistently in transnational campaigns to mobilize support of the global community. The reasons, I believe, are two-pronged: first, and this is particularly true to the Bangladesh context, organizing against acid violence really took off in post-Beijing era where women's NGOs in the Global South were able to use international human rights instruments - such as the Platform of Action with its specific mandate on the "girl child" - to urge governments to act; second, and by no means less critical, is the power of the "spectacular violence against women" narrative in human rights advocacy that elicits humanitarian action on behalf of the third world victim subject. The reining in of young women's sexuality through seemingly patriarchal violence of acid attacks generate more attention and fit a certain script of "third world violence" within the apparatus of human rights, which frequently resurrect colonial tropes of "victim" "savage" and "savior." Legal scholar Makau Mutua (2011) calls the constellation a three-pronged metaphor where the victim and savage are located within third world cultures and the savior in the enlightened West. Even as these familiar narratives can bolster human rights campaigns by mobilizing international support, they can impede in mounting a layered response whereby 
processes of neoliberalism and economic restructuring, which have been studied as factors making women's lives more insecure and vulnerable to interpersonal and structural violence, are left unquestioned. Thus, focusing on the adolescent third world victim subject can elicit more speedy and concerted humanitarian intervention, yet at the same time it can underemphasize broader structural questions.

Pointing to the inattention to global power relations when analyzing gendered violence in the Global South, Kamala Visweswaran (2004) posits that human rights reporting with regards to South Asia tends to rely on the language of universal feminism and human rights, reducing this region, and the nations and states within, to a static set of cultural practices that are not only excessively harmful to women but also erase the long history of democratic contestations and feminist activism on behalf of women in the countries in question. Moreover, the role of political conflict in exacerbating gender discriminatory practices in distinct local contexts are subsumed under the catchall explanation of what Uma Narayan (1997) calls "death by culture." Such strategies foregrounding gender essentialism, albeit important in mobilizing support for women, tend to extricate women's rights from those of their community and nation state and relocate them "in an abstract international realm" that perpetuates the age-old colonial logic famously articulated by Gayatri Spivak (1988) of saving brown women from brown men (Visweswaran, 2004, p. 484). Merry (2006) has cogently demonstrated in her ethnography of the UN that activists resort to using culture as an alibi to mount human rights advocacy campaigns. In this way, the use of culture both bolsters and impedes human rights advocacy in campaigns against gender violence. The other side of this narrative is the obscuring of violence against women in the Global North and the inextricable ways in which violence against women worldwide is linked to global economic restructuring and neoliberalism. In addition, this cultural script underemphasizes the role of political conflict in exacerbating gender discriminatory practices. In case after case in the ASF report, while misogyny certainly played a role in the mode of violence chosen, equally culpable in the design of this mode of violence was the fact that perpetrators knew that they were protected because of their status (that of being affiliated to powerful political parties). In contrast, however, most human rights policy reports tend to downplay political conflict and overemphasize the notion of honor and shame as patriarchal cultural enforcers keeping women in South Asia more silent and therefore victimized. Kamala Visweswaran's eloquent questions are critical reminders here of a double standard where women in the Global South are considered exclusively to be victims of human rights abuse based on culture. She asks:

First, what would it mean to understand domestic violence [and, I would add here, gender violence in general] in South Asia and its narrative production, as a product not only of culture, but of state-level policy and the neo-liberal economy? Second, what would it mean to speak of a culture of violence against US women, and to understand domestic violence in the United States as a human rights issue? (p. 511)

Attending to these questions aids in the shifting of the discourse of gender violence, particularly acid violence, from a purely culturalist to a much needed structural analysis. 


\section{National Realities of Acid Attacks}

Acid attacks against women have been reported in many countries around the world including in the continents of North America, Africa, Europe and Asia. Bangladesh, India, and Cambodia are among the nations with the highest frequency of acid violence. While there are common patterns to the phenomenon across the region of South and Southeast Asia, there are also important differences, and looking at what is happening in Bangladesh specifically can help us to better understand the experiences of the survivors recorded by the ASF. According to a report by researchers Kalantry and Kestenbaum released by the Avon Global Center for Women and Justice (2011), since 1999, there have been roughly 3,000 reported cases of acid attacks in Bangladesh (p. 10). These numbers, however, are not entirely reliable as not every case of acid attack is reported. Governments do not maintain statistics on acid attacks, a task usually undertaken by different NGOs that at times yield reports with varied information. Perpetrators, particularly in India and Bangladesh, are predominantly men, constituting more than $80 \%$. (p. 14). In Bangladesh, nearly $60 \%$ of victims are between the ages of 10 and 19 (p.12). Often these children are unintended targets who are hit as a result of being close to the intended targets.

Acid violence is perceived to be a gender-based violence with women and girls constituting the majority of the victims with their lower social, economic and political status contributing to their overall vulnerability, though the story is much more complex. When the Acid Survivor Foundation (ASF) in Bangladesh researched the causes of acid violence, their study indicated that only $17 \%$ of the acid attacks in Bangladesh over the time period of 19992002 was caused by rejection of love, marriage or sex proposals (Acid Survivors Foundation Annual Report, 2009, p. 16). A study of newspapers in India indicated only $35 \%$ of attacks were by rejected male suitors, yet this is the profile of the crime that seems to make it in to media and policy reports with persistent regularity (Kalantry and Kestenbaum, 2011, p. 20). This particular profile perhaps overemphasizes the violence within the framework of culture. The assumption here is that men in patriarchal societies cannot handle rejection and therefore brutalize women who dare to transgress cultural code of conduct. In reality, land and business disputes are the leading causes for acid violence, and older women are frequently targeted as a means to desecrate families involved in these disputes.

Two of the cases studies in the ASF commissioned report involve young womenRupabanu and Chandbanu, both in their teens when the attack occurred. A cousin who wanted to marry Rupabanu splashed her with acid 20 days after her marriage to an NGO worker. She says that her parents arranged her marriage to this man very quickly to protect her from her cousin's advances. It is evident that Rupabanu's family held a higher status as they lived in their own house but her cousin's father was a farm worker. Her cousin's mother was eager to have her as a daughter-in-law but did not have the courage to approach the family. Rupabanu's family aspired to marry her to a government employee. She attended school, was good-looking and came from a more financially solvent family than her cousin, Anis, whom she describes as a 'mastaan' who did not work nor study and was involved with a political group. This political affiliation gave him clout and he even went as far as to threaten to carry Rupabanu off in a car if her parents arranged her marriage elsewhere.

Chandbanu was also a teenager when she was attacked by Abdul who had worked in her father's handloom factory. His proposal to marry Chandbanu was turned down by her family as they did not consider him a suitable match. Chandbanu was a student of Class Seven at the time. Following the rejection, Abdul stopped working in the factory. He made many threats about destroying her face and that nobody else could marry her. The night of the attack, he came with 


\section{Chowdhury: Rethinking Patriarchy, Culture and Masculinity}

two other young men and threatened the neighbors to not help Chandbanu. In both these cases, it is relevant to pay attention that the women are more educated and from higher socioeconomic status. The men wielded influence through affiliation to political party and other men. Even greater than the promise of male provision is the notion of male protection without which women would be deemed unworthy of respect and at greater risk (Kabeer, 2000, p. 187).

Because the violence is often rooted in various structural inequalities, men can also be victims of acid violence. The ASF report cites two cases where the victims are male. In one, Kabil, a fifty year old man, was attacked when he tried to save his daughter-in-law from Ali, his step-daughter's former husband. This outcome was a result of a long and complicated animosity between Kabil, Ali, and the step-daughter. Ali had tried to get Kabil arrested on false charges numerous times. He had brutally shot and murdered the second husband of Kabil's stepdaughter. The step-daughter complicit in these crimes had been continuing a relationship with her former husband even after her second marriage. The couple was angry for being cut off financially by the dead husband's brother and wanted revenge. She helped Ali lure Kabil's daughter-in-law into the jute fields where he tried to rape her presumably to inflict further harm to the family. When Kabil intervened, he was attacked with a knife and then splashed with acid. And, it is not clear for whom the acid was intended: for Kabil or his daughter-in-law. In the report Ali is stated to have affiliation with a political party emboldening him in his criminal activities - a characteristic that was also shared by all of the perpetrators.

The second case involving an eighteen year-old man, Rahman, appears to be linked to a dispute over land and money between step-brothers. Rahman's father had two wives. The perpetrator was the son of the first wife. He was older, had multiple wives and therefore felt more entitled to his father's property. All the wives and the children resided in the same household and Rahman's father controlled the finances tightly. The family was financially solvent and owned a lot of land. However the perpetrator seemed to squander money and get into trouble with the law quite frequently. He also had connections to a political party. When Rahman's father gave Rahman a piece of land to plough and earn his keep, the older brother became angry. He felt that as a bachelor Rahman had no need for land and that it should have been his brother with the rights to plough. He splashed Rahman with acid at night while he slept. The older brother wanted to teach him a lesson and punished him by marking him permanently - an expression of gendered power - not unlike the ways in which women are frequently marked by their abusers.

Despite these examples and because of the ways that inequalities often intersect, it is disproportionately women family members who are made to pay the price for the kinds of disputes that cause violence. Because women are considered carriers of culture, they are singled out not only as a way to send a message of shame and defilement but also to further devalue their gendered status and to bring economic hardship to the family. That women are more likely to be burnt on the face - as opposed to other parts of the body as is the case with male victims of acid attack - is a sign of both their social and economic vulnerability. Political and historic forces exacerbate this vulnerability. Whereas historically in South Asia the groom's family paid money or gave gifts to the bride's family upon marriage, processes of industrialization, consumer capitalism, and labor migration have reversed the trend (Kabeer, 2000, p. 60). As women are increasingly perceived as economic burdens, unmet dowry demands and other forms of domestic disputes are met with violence and abuse towards them. Processes of globalization have frequently made women's positions less secure and weakened the so called "patriarchal contract" or men's obligation towards women and their families. 
While Bangladesh does have the Acid Survivors Foundation dedicated to meet the multipronged needs of victims, medical, legal, or rehabilitative services available for victims are still woefully scarce. One problem is that there is widespread ignorance about treating acid burns. The fact that washing the wounds with water in the immediate aftermath of acid burns significantly minimizes damage is not well known among health care professionals (particularly at the local levels), let alone the lay public. Nurun Nahar, a survivor in Bangladesh told me that her family tried to wash her wounds with Dettol, an anti-septic, which caused her more pain and wounding (N. Nahar, personal communication, April 2003). One study in Bangladesh found that $71.5 \%$ of burn victims had "grossly infected wounds" indicating lack of proper treatment (Kalantry and Kestenbaum, 2011, p. 39). In my own research in Bangladesh, I came across many patients who told me that doctors refused to treat them for fear of retaliation by the same perpetrators. Some of these perpetrators were sheltered by powerful political leaders who enabled them to falsify police reports and bribe state agents not to file charges. Families of victims faced routine harassment and threats from the perpetrators and their associates and relatives. Treatment for acid burns requires long-term care and multiple surgeries stretching over several months, if not years - a process particularly costly and challenging for victims who, on top of the horrific injuries, faced fear, shame and lack of resources when pursuing redress. In the case of children in particular, whose bodies are still growing, skin grafting surgeries must take place in routine intervals.

Another problem that victims face is that they are not always protected by the laws in their countries. Legislation for criminal prosecution of acid violence perpetrators was introduced in Bangladesh in 1984 and in 2002 the Acid Crime Control Act and the Acid Control Act were enacted. This legislation demands heightened penalties and special court procedures for acid attack cases as well as "regulate[s] and monitor[s] the use, sale, purchase, storage, transportation, import, and export of acid in Bangladesh" (Kalantry and Kestenbaum, p. 27). While it is commendable that since the introduction of these new laws Bangladesh has seen a $20 \%$ decrease in acid violence, the legislation nevertheless needs critical evaluations both at the levels of both practical implementation and conceptual framework (Kalantry and Kestenbaum, p. 2). In terms of implementation, fewer than one in five acid attack perpetrators in Bangladesh have been convicted. Despite the existence of Acid Control Act for nearly a decade, in Bogra, only 31 out of an estimated 2,800 acid users have licenses. In Satkhira, a district with high acid violence prevalence, only five out of 100 shops that sell acid have a license (Kalantry and Kestenbaum, p. 29).

With regard to the framing of the law, victims' bodies are objectified and compartmentalized to body parts with loss or damage to certain parts deemed worthy of higher punishment. The degree of punishment to be meted out to the perpetrator is measured against the specific injuries to the victim. For example, sentences of death penalty or life imprisonment, and a fine of up to Tk. 100,000 (\$1,450 USD) are given if the victim loses hearing or sight or if their face, breasts, or sexual organs are affected. Injuries to any other part of the body are met with 414 years of imprisonment and a fine of up to Tk. 50,000 (\$700 USD) (Kalantry and Kestenbaum, p. 27). By equating the more severe punishment with the degree of injury, and considering sexual organs as more important than other body parts, the law fails to ascertain the integrity and quality of human life as a whole. Additionally, in cases where the victim has lost her chances of marriage and to be a mother, judges are more prone to impose stringent punishment on the accused. In this way, the assumption that women's primary roles in society are those of mother and wife are validated. Obstacles on so many levels send out a message that women are weak 
and exploitable and that perpetrators will not be convicted. These are urgent reminders that implementation and regular monitoring of law leave much to be desired.

Institutionalized biases and ineffective legal mechanisms became apparent to me in my discussions with ASF staff in Bangladesh. The Acid Control Act of Bangladesh demands special tribunals for acid cases where investigations must be completed within 30 days, with provision for up to 60-day extension. Trial proceedings must be completed within 90 days from the date of receipt of the case (Chowdhury, 2011, p.73). If the proceedings are not completed within this timeframe, which they often are not, the accused can be released on bail. My discussions with the legal coordinator of the Acid Survivors Foundation revealed that the police were overburdened and the 90-day timeframe put serious pressure on them, particularly in light of the fact that in Bangladesh, there is about one police officer for every 1,138 inhabitants (Kalantry and Kestenbaum, p. 29).

In the various cases I have tracked in my research, common patterns emerged where victims and their families had to pay bribes to file a complaint or the First Information Report (FIR). Information on the FIR was often falsified by the police upon threat and intimidation by powerful perpetrators and their political associates. Victims and families were threatened and offered money and even marriage of victim to perpetrator as a means to keep them silent and drop charges. I came across cases where young girls were married off to the same men who had thrown acid at them because their families found that to be the most logical arrangement in a situation where they lacked social and economic security and were faced with a legal system to which they had minimum access. Complicated, lengthy and inadequate forensic procedures contributed to delays in filing charges giving perpetrators more time to flee. There is only one police laboratory in Dhaka for the entire country. In many cases in India and Bangladesh, victims had filed complaints against the perpetrator prior to the attack for harassment, but the police neglected to take any action. Acid victims expressed hesitation in contacting the police because of fear of harassment, ridicule and victim-blaming. The convener of a leading women's NGO in Bangladesh told me that the Police Commissioner of Dhaka had expressed to her the opinion that "Women are like fragrant flowers. It is only natural that men will pursue them" (Anonymous, personal communication, April 2003).

While legal structures are important, they are hardly effective when inaccessible or irrelevant to the vast majority of the population, namely women and the poor. Gender and class biases are institutionalized in the social and legal structures, which mere enactment of law cannot transform. Furthermore, the state occupies an ambiguous role through the provision of antiviolence legislation while failing to secure processes for its effective implementation. In Bangladesh, most interventions have been in the medical and legal fronts without adequate attention to the pervasive social and economic vulnerabilities of women. These laws are hardly commensurate with the long term social isolation, stigmatization, discrimination and loss that acid violence survivors, particularly women and girls, experience. In the case of young teenaged victims, they often have to stop going to school either because of severe health issues or the social stigma that ensues thus limiting their social mobility through a lack of education. Bina Akhter, a teenaged survivor from Bangladesh, told me that she was teased relentlessly about her appearance on the streets. She was even likened to a "monkey in a zoo" (B. Akhter, personal communication, December 2004). Speaking to the specific losses adolescent girls experienced, Nasreen Huq, the coordinator of the acid campaign at the time told me, "It is important to recognize that these are children we are talking about. They have a right to live their childhood. They have a right to be on the streets" (N. Huq, personal communication, April 2003). Her 
observation here reminds us of the urgency of human rights advocacy that address deep-rooted gendered and structural inequalities.

\section{Conclusion}

In Huq's comment above, she encourages recognition of the multiple and complex layers to structural inequalities in designing meaningful services for victims/survivors of violence. Such an approach is embedded in Karin Landgren's (2005) broad framework to protect vulnerable groups, including children, from violence, abuse, and exploitation, which includes not only attention to harmful "traditional practices" but also more effective national and international commitment. In addition, she urges expanding palliative responses focusing on legal reform and service delivery to preventive approaches towards systemic change. She suggests a closer cooperation between the human rights and development communities as a crucial strategy.

It is important to emphasize both the centrality of human rights to development initiatives and the critical relationship between human rights and national development. To that end, Landgren proposes eight interlinked elements for creating and strengthening a secure environment for the vulnerable: government commitment and capacity, legislation and enforcement, culture and customs, open discussion, life skills, knowledge, and participation, capacity of families and communities, essential services, and monitoring, reporting and oversight (p. 227). While some of these may appear to be commonsensical, the comprehensive and integrated approach is key. It would create legislation as well as mechanisms for enforcement and oversight, approach cultural change in tandem with open dialogue, and promote life skills development with provisions for services and the capacity building of families and communities.

An additional area that is increasingly becoming more important is the role of the private sector in promoting and securing human rights, particularly for vulnerable groups. This is especially important given the role of transnational corporations in ongoing economic neoliberal restructuring wreaking havoc on marginalized populations in the Global South. Here, the Avon Global Center Report's (2011) recommendation to require corporations to act with due diligence to prevent violations of international human rights law is important. The report reminds us that even when 'governments have not adopted laws to protect citizens' human rights, businesses are not free of a responsibility to act" (Kalantry and Kestenbaum, 2011, p. 45). Given that acid violence is recognized as a gender-based violence prohibited by international human rights law, states are obligated to act to prevent acid attacks. Companies that operate in countries where acid attacks are a problem must ensure safe practices surrounding its sale, storage, use, and purchase. In this way, the private sector must be held more accountable for their operations and practices.

Nurun Nahar, now 32, a survivor of an acid attack in 1995 and an activist and counselor to acid victims in Bangladesh, remembers lying in a hospital bed and thinking of "The school pranks, walks, giggles, exam notes, teenage dreams." The message she now conveys to other survivors is, "It will hurt; you might not recognize your face, but if I can get through, so will you" (Das, 2011). Hawa Akhter, who went on to sit for her exams said in an interview, "My right hand has been cut off, but I can use my other hand" (Buncombe, 2011). "With my legal experience in Bangladesh, I was thinking if I could be a lawyer, I could better represent myself," said Rumana Manzur who is studying law at the University of British Columbia (Wells, 2013). Indeed, these individual acts of resistance, struggle, and survival should not go unmentioned in our investigation of gender violence and human rights. Tracing these individual stories of victimization and survival is key to understanding the multi-faceted phenomenon of gender- 
based violence and for developing just advocacy pathways. Broadening our analytic framework to address structural inequalities can aid in building better services and societies for vulnerable groups. 


\section{Works Cited}

Acid Survivors Foundation. (2007). Conflict dynamics of acid violence: 10 case studies on conflicts dynamics of acid (patriarchal) violence in Bangladesh. Dhaka, Bangladesh: ASF.

Acid Survivors Foundation. (2009). Annual report. Dhaka, Bangladesh: ASF.

Buncombe, A. (2011, December 16). Bangladesh man accused of cutting off wife's hand. The Independent. Retrieved from http://www.independent.co.uk/news/world/asia/bangladeshman-accused-of-cutting-off-wifes-hand-6278155.html.

Chowdhury, E. H. (2005). Feminist negotiations: Contesting narratives of the campaign against acid violence in Bangladesh. Meridians: Feminism, Race, Transnationalism, 6(1), 162193.

Chowdhury, E. H. (2011). Transnationalism reversed: Women organizing against gendered violence in Bangladesh. Albany, NY: SUNY Press.

Das, B. (2011, May 3) Acid-attack survivor heals inner scars of others. Wenews. Retrieved from: www.womensenews.org.

Ethirajan, A. (2011, December 15). Bangladesh man 'admits' cutting off wife's fingers. $B B C$ News. Retrieved from: http://www.bbc.co.uk/news/world-asia-16201961

Farmer, P. (2005). Suffering and structural violence. In P.S. Rothenberg (Ed.), Beyond borders: Thinking critically about global issues (pp. 368-384). New York, NY: Worth Publishers.

Grewal, I. (2013). Outsourcing patriarchy: Feminist encounters, transnational mediations and the crime of 'honor killings.' International Feminist Journal of Politics, 15(1), 1-19.

Hesford, W. (2004). Documenting violations: Rhetorical witnessing and the spectacle of distant suffering. Biography, 27(1), 104-144.

Hossain, M. (2014, January 23). The first government sponsored survey on violence against women: Women more oppressed at home. Prothom Alo. Retrieved from http://www.prothom-alo.com/we_are/article/129712\%.

Kabeer, N. (2000). The power to choose: Bangladeshi women and labour market decisions in London and Dhaka. London, England: Verso.

Kalantry, S. \& Kestenbaum, J. G. (2011). Combating acid violence in Bangladesh, India, and Cambodia (Paper 1). Ithaca, NY: Avon Global Center for Women and Justice and Dorothea S. Clarke Program in Feminist Jurisprudence. Retrieved from: http://scholarship.law.cornell.edu/avon_clarke/1.

Landgren, K. (2005). The protective environment: Development support for child protection. Human Rights Quarterly, 27, 214-248.

Merry, S. (2006). Human rights and gender violence: Translating international law into local justice. Chicago, IL: University of Chicago Press.

Merry, S. (2009). Gender violence: A cultural perspective. Hoboken, NJ: Wiley-Blackwell Publishers.

Mutua, M. (2011). Savages, victims, and saviors: The metaphor of human rights. Harvard International Law Journal, 42(winter), 201-246.

Narayan, U. (1997). Dis-locating cultures: Identities, traditions, and third-world feminism. New York, NY: Routledge.

Nomani, A. Q. (2011, July 16). Mauled by her husband? The Daily Beast. Retrieved from: http://www.thedailybeast.com/articles/2011/07/16/muslim-honor-crimes-rumanamonzur-allegedly-mauled-by-her-husband.html 
Saleh, A. (2011, June 15). Whose face are we saving? Bdnews24. Retrieved from: http://opinion.bdnews24.com/2011/06/15/whose-face-are-we-saving/

Schaffer, K. \& Smith S. (2004). Human rights and narrated lives. New York, NY: Palgrave MacMillan.

Spivak, G. C. (1988). Can the subaltern speak? In C. Nelson \& L. Grossberg (Eds.), Marxism and the interpretation of culture, Chicago, IL: University of Illinois Press, pp. 271-313.

Stone-Mediatore, S. (2002). Reading across borders: Storytelling and postcolonial struggles. New York, NY: Palgrave Macmillan.

Visweswaran, K. (2004). Gendered states: Rethinking culture as a site of South Asian human rights work. Human Rights Quarterly, 26, 483-511.

Wells, K. (2013, October 25). Blinded UBC law student now in her 'comfort zone.' CBC News. Retrieved from: http://www.cbc.ca/news/blinded-ubc-law-student-now-in-her-comfortzone- 1.2252020 